\title{
Liquid-liquid equilibria in aqueous two-phase ethanol/salt systems at different temperatures and their application to anthocyanins extraction
}

\author{
Ana Clara Rocha CALDEIRA ${ }^{1}$, Wanderley Filho Lopes de FRANCA ${ }^{1}$, Attilio CONVERTI ${ }^{2}$ (D), \\ William James Nogueira LIMA ${ }^{1}$, Fábio Coelho SAMPAIO ${ }^{3}$, Janaína Teles de FARIA ${ }^{1 *}$
}

\begin{abstract}
Aqueous two-phase systems (ATPS) are formed by mixtures of chemical species that, under certain conditions, separate into two immiscible phases, with water as the major component in global terms and, at lower concentrations, polymers, salts, ionic liquids and alcohols, depending on the system type. Different parameters influence ATPS equilibrium such as temperature, alcohol carbon chain size, salt type, $\mathrm{pH}$, etc. The present work aimed to obtain the binodal curves for ATPS made up of ethanol, sodium citrate/ammonium sulfate and water at different temperatures $\left(15,25\right.$ and $\left.35{ }^{\circ} \mathrm{C}\right)$ as well as to evaluate the potential of the ethanol/ammonium sulfate system in anthocyanins partition. The results showed that the increase in temperature did not alter the biphasic region in the temperature range investigated, not influencing the formation of phases. Nonlinear equations were satisfactorily fitted to binodal curves data, except for sodium citrate-containing ATPS at $15^{\circ} \mathrm{C}$. Higher concentration of the overall mixture resulted in longer tie-line of ammonium sulphate-containing ATPS. Higher values of partition coefficient and recovery yield of Syzygium cumini fruit anthocyanins were obtained at longer tie-lines.
\end{abstract}

Keywords: biphasic region; phase equilibrium; liquid-liquid extraction.

Practical Application: Food application as an additive agent in processed foods for humans or animals.

\section{Introduction}

Aqueous two-phase systems (ATPS) are composed of two hydrophilic components such as polymers with different chemical structures (Albertsson, 1958), polymer and salt (Pereira et al., 2013), ionic liquid and salt (Shukla et al., 2018) or alcohol and salt (Lo et al., 2015), which under certain thermodynamic conditions lead to the spontaneous formation of two immiscible phases when at rest.

ATPS formation was first observed by Beijerinck in 1896, when he mixed aqueous solutions of polymers (starch and gelatin, agar-agar and gelatin) (Iqbal et al., 2016). Studies have then been carried out using different types of polymers, which combined at certain concentrations leading to phase separation (Oliveira et al., 2018). However, only in the 1960s it was reported the potential application of ATPS to recover biomolecules (Albertsson, 1958). Since then, ATPS have been used in different studies on microorganisms (Ascon-Cabrera \& Lebeault, 1993), cancer cells (Atefi et al., 2015), enzymes (Tonova \& Bogdanov, 2017) and natural dyes such as, for example, anthocyanins (Qin et al., 2017) and carotenoids (Freire et al., 2011), among others.

The use of ATPS has been suggested as an alternative to the conventional methods of extraction and purification of several biomolecules of technological and industrial concern (Shukla et al., 2018), owing to several advantages offered by them, among which are reduced number of separation steps, lower costs and higher purity of recovered products (Oliveira et al., 2018). In addition, phases are constituted mainly by water, which makes the environment milder for biomolecules, preserving and maintaining their biological activity (Asenjo \& Andrews, 2011).

ATPS stand out as an important emerging technology to extract and purify biomolecules (Wu et al., 2011), allowing to achieve high product purity and yield, maintaining biological activity (Albertsson, 1958). ATPS made up of short chain alcohols and salts offer additional advantages such as low interfacial tension, low phase viscosity (which speeds up phase separation), ease scale up and low energy consumption (Reis et al., 2014). Moreover, they make the recovery of the target compound from the alcohol-rich phase easier (Wang et al., 2010b), with the possibility of recycling alcohols and salts by evaporation and extractive crystallization, respectively (Guo et al., 2012; Nemati-Kande et al., 2012; Show et al., 2013), hence reducing purification and concentration costs.

Among the pigments that can be partitioned using ATPS are anthocyanins, which are found naturally in red, purple and blue flowers and fruits used in folk medicine to prevent diseases or as food (Khoo et al., 2017). When highly bioavailable, they efficiently reduce cellular lipid peroxidation and, consequently, the risks of many diseases, thereby justifying their nutraceutical 
and pharmaceutical importance (Khoo et al., 2017). However, undesired substances are co-extracted during partitioning (Chandrasekhar et al., 2012; Jampani et al., 2014; Wu et al., 2011), some of which may cause pigment degradation during storage or hamper downstream processes (Chandrasekhar et al., 2012; Liu et al., 2004). Then, a purification step is required, for which ATPS can be used as an alternative to the traditional liquid-liquid extraction with organic solvent.

However, the use of ATPS to concentrate and purify biocompounds requires knowledge of the liquid-liquid equilibrium data as well as the target molecule distribution in the systems, so that profitable and productive extraction processes can be designed (Khayati \& Gholitabar, 2016). Thus, in the present work, equilibrium data of ATPS made up of ethanol and sodium citrate/ammonium sulfate were obtained at different temperatures to evaluate the effect of temperature on liquid-liquid equilibrium. In addition, ATPS composed of ethanol and ammonium sulfate were used to partition anthocyanins from Syzygium cumini fruits.

\section{Materials and methods}

\subsection{Chemicals and materials}

Fruits of Syzygium cumini (jamun) at maturation stage were harvested from the trees present at the Federal University of Minas Gerais (UFMG) campus of Montes Claros, MG, Brazil. Fruits were stored in polypropylene packages and kept at $-25^{\circ} \mathrm{C}$ until use. Ethanol (purity > 99.5\%) was purchased from Merck (Darmstadt, Germany), hydrochloric acid and tribasic sodium citrate (purity > 99\%) from Êxodo (São Paulo, SP, Brazil) and ammonium sulfate (purity > 99\%) from Synth (São Paulo, SP, Brazil). All chemicals used in the experiments were analytical grade reagents. Deionized water (Synergy UV, Millipore, Molsheim, France) was used in all experiments.

\subsection{Binodal curves and equilibrium data}

Equilibrium diagrams of the systems composed of ethanol, sodium citrate and water and of ethanol, ammonium sulfate and water were obtained by turbidimetric titration (Albertsson, 1986) at atmospheric pressure and temperatures of 15,25 and $35^{\circ} \mathrm{C}$. Stock solutions of ethanol $(80 \% \mathrm{w} / \mathrm{w})$ and sodium citrate or ammonium sulfate $(30 \% \mathrm{w} / \mathrm{w})$ were prepared in an analytical balance (AW220, Marte, São Paulo, SP, Brazil) with $\pm 10^{-4} \mathrm{~g}$ accuracy. Approximately $1.0 \mathrm{~g}$ salt (or ethanol) stock solution was weighed into a test tube, kept partially immersed in a thermostatic bath (Q214M2, Quimis, São Paulo, SP, Brazil) at the working temperature, and titrated with $50-\mu \mathrm{L}$ aliquots of stock ethanol (or salt) solution under manual agitation until turbidity appeared (indicative of biphasic mixture). Then, $50-\mu \mathrm{L}$ aliquots of deionized water were added with a micropipette to the turbid mixture, under constant manual agitation, until turbidity disappeared (indicative of single-phase mixture). The number of added titrant and water aliquots was recorded to determine the mass balance of system components at each identified cloud point. This procedure was repeated until enough points were obtained to construct the curve.
The following models (1-3) were fitted to the experimental data of binodal curves (Michel et al., 2015; Wang et al., 2010a):

$$
\begin{aligned}
& {\left[w_{1}\right]=A \exp \left[\left(B\left[w_{2}\right]^{0.5}\right)-\left(C\left[w_{2}\right]^{3}\right)\right]} \\
& {\left[w_{I}\right]=A+B\left[w_{2}\right]^{0.5}+C\left[w_{2}\right]}
\end{aligned}
$$

$\left[w_{1}\right]=A+B\left[w_{2}\right]^{0.5}+C\left[w_{2}\right]+D\left[w_{2}\right]^{2}$

where $\left[w_{I}\right]$ is ethanol concentration $(\% \mathrm{w} / \mathrm{w})$ in the mixture, $\left[w_{2}\right]$ is sodium citrate or ammonium sulphate concentration $(\% \mathrm{w} / \mathrm{w})$ in the mixture and $A, B, C$ and $D$ are the coefficients estimated by regression.

\subsection{Determination of tie-lines}

Tie-lines obtained with the phase-forming components at different concentrations in the top and bottom phases were determined by the gravimetric method originally proposed by (Merchuk et al., 1998). For this purpose, the "lever rule" was applied to the relationship between mass composition in the top phase and overall system composition. Three ATPS composed of ethanol, ammonium sulfate and water at $25^{\circ} \mathrm{C}$ were chosen based on the biphasic region and prepared by weighing appropriate amounts of water and stock solutions of ethanol and ammonium sulfate in $15-\mathrm{mL}$ centrifuge tubes to obtain $12-\mathrm{g}$ systems. The tubes were shaken vigorously and let to rest in a thermostatic bath at $25^{\circ} \mathrm{C}$ for $1 \mathrm{~h}$. The top and bottom phases were carefully separated and weighed, the bottom one being carefully collected with the aid of a long needle syringe. The concentrations of the components of each phase were determined by the following system of four equations (4-7) and four unknowns $\left(\left[w_{1}\right]_{t},\left[w_{1}\right]_{b},\left[w_{2}\right]_{t}\right.$ and $\left.\left[w_{2}\right]_{b}\right)$ :

$$
\begin{aligned}
& {\left[w_{1}\right]_{\mathrm{t}}=A+B\left[w_{2}\right]_{\mathrm{t}}^{0.5}+C\left[w_{2}\right]_{\mathrm{t}}+D\left[w_{2}\right]_{\mathrm{t}}^{2}} \\
& {\left[w_{1}\right]_{b}=A+B\left[w_{2}\right]_{t}^{0.5}+C\left[w_{2}\right]_{b}+D\left[w_{2}\right]_{b}^{2}} \\
& {\left[w_{1}\right]_{t}=\left[\alpha\left(\left[w_{1}\right]_{m}-\left[w_{1}\right]_{b}\right)\right]+\left[w_{1}\right]_{m}} \\
& {\left[w_{2}\right]_{m}=\left[\alpha\left(\left[w_{2}\right]_{b}-\left[w_{2}\right]_{m}\right)\right]+\left[w_{2}\right]_{t}}
\end{aligned}
$$

where the subscripts $t, b$ and $m$ do refer to top phase, bottom phase and overall mixture, respectively, $\alpha$ is the ratio of the bottom phase mass to the top phase one, and $A, B, C$ and $D$ are the best fit regression coefficients.

The length (TLL) and slope (STL) of tie-line of the three systems under consideration were calculated by the Equations (8 and 9) (Iqbal et al., 2016):

$T L L=\left[\left(\left[w_{1}\right]_{t}-\left[w_{1}\right]_{b}\right)^{2}+\left(\left[w_{2}\right]_{t}-\left[w_{2}\right]_{b}\right)^{2}\right]^{0.5}$ 


$$
S T L=\frac{\left[w_{1}\right]_{t}-\left[w_{l}\right]_{b}}{\left[w_{2}\right]_{t}-\left[w_{2}\right]_{b}}
$$

\subsection{Preparation of anthocyanins extract from Syzygium cumini fruit peel}

Fruits of Syzygium cumini (jamun) were duly sanitized in running water and dried, and the peel was removed manually to extract anthocyanin. About $140 \mathrm{~g}$ of fruit peel were extracted for $24 \mathrm{~h}$ at room temperature in the dark with $280 \mathrm{~mL}$ of water acidified with hydrochloric acid $(\mathrm{pH}=2.0)$, under constant stirring (200 rpm) in orbital incubator/shaker (Lucadema, São Paulo, SP, Brazil). The extract obtained was then vacuum filtered through qualitative paper and concentrated by lyophilization (Martin Christ, Osterode, Germany). The concentrated extract was aliquoted/fractionated in Eppendorf tubes and kept under freezing, protected from light, until use.

\subsection{Anthocyanins partition in ethanol/ammonium sulfate ATPS}

Anthocyanins were partitioned in ATPS composed of ethanol and ammonium sulfate at $25^{\circ} \mathrm{C}$, in the three tie-lines as described in section 2.3. For this purpose, $2.0 \mathrm{~mL}$ of the top and bottom phases were used to compose the partition system. One hundred $\mu \mathrm{L}$ of anthocyanins extract were added to the tubes containing $2.0 \mathrm{~mL}$ of each phase. Tubes were shaken vigorously and let to rest in thermostatic bath at $25^{\circ} \mathrm{C}$ for $1 \mathrm{~h}$. Afterwards, the phases were collected separately with a long needle syringe for determination of anthocyanins concentration.

The partition coefficient $\left(k_{a}\right)$ is defined as the ratio between anthocyanins concentration in the top $\left([\mathrm{ant}]_{\mathrm{t}}\right)$ and bottom $\left([\mathrm{ant}]_{\mathrm{b}}\right)$ phases, according to the Equation (10) (Wu et al., 2014):

$k_{a}=\frac{[\mathrm{ant}]_{\mathrm{t}}}{[\mathrm{ant}]_{\mathrm{b}}}$

To select the system with the best anthocyanins extraction capacity, we calculated the theoretical recovery yield in the top phase $\left(\mathrm{Y}_{\mathrm{t}}, \%\right)$ as the ratio between the mass of compound partitioned to the top phase and its total mass in the system (11) (Ooi et al., 2009):

$\mathrm{Y}_{\mathrm{t}}=100\left(\frac{\mathrm{k}_{\mathrm{a}} \mathrm{R}_{\mathrm{v}}}{1+\left(\mathrm{k}_{\mathrm{a}} \mathrm{R}_{\mathrm{v}}\right)}\right)$

where $R_{v}$ is the ratio between the volumes of the top and bottom phases.

\subsection{Determination of anthocyanins concentration}

The concentration of total anthocyanins in the phases was determined directly by the spectrophotometric method of differential pH (Hosseinian et al., 2008). Samples were five-times diluted in two buffer solutions, one at $\mathrm{pH} 1.0(0.03 \mathrm{M}$ potassium chloride buffer) and one at $\mathrm{pH} 4.5(0.4 \mathrm{M}$ sodium acetate buffer). Diluted solutions were allowed standing for $30 \mathrm{~min}$, and their absorbance was read at 520 and $700 \mathrm{~nm}$ with a UV-Vis spectrophotometer (UV-1280, Shimadzu, Kyoto, Japan). Anthocyanins concentration ([ant], mg/L) was calculated by means of the following Equation (12) and expressed as cyanidin-3-glucoside equivalent:

$[$ ant $]=\frac{A \times M M \times D F \times 1000}{\varepsilon \times L}$

where $A$ is the total absorbance determined as $\left(\mathrm{ABS}_{520}-\mathrm{ABS}_{700}\right)_{\mathrm{pH} 1.0}-\left(\mathrm{ABS}_{520}-\mathrm{ABS}_{700}\right)_{\mathrm{pH} 4.5}, M M$ the anthocyanins molar mass considered as cyanidin-3-glucoside $(449.2 \mathrm{~g} / \mathrm{mol})$, $D F$ the dilution factor, $\varepsilon$ the molar extinction coefficient $(26,900 \mathrm{~L} / \mathrm{cm} . \mathrm{mol})$ and $L$ the cuvette optical path $(1 \mathrm{~cm})$.

\subsection{Statistical analysis}

All experiments were performed in triplicate, and the results expressed as means \pm standard deviations. The significance of models described by Equations 1-3 was assessed by the analysis of variance ( $p$-value $<0.05$ ), the quality of adjustment by both the coefficient of determination $\left(R^{2}\right)$ and root-mean square error (RMSE), and the significance of regression coefficients by the $t$-test $(p$-value $<0.05)$.

\section{Results and discussion}

\subsection{Phase diagrams of ethanol/ammonium sulfate and ethanol/sodium citrate ATPS}

The binodal curves of aqueous two-phase systems (ATPS) composed of ethanol/ammonium sulfate and ethanol/sodium citrate at 15,25 and $35^{\circ} \mathrm{C}$ are shown in Figure 1, panels A and B, respectively. A temperature increase did not lead to significant variations in either their shape or position, not interfering in the biphasic region (above the binodal curve) of the investigated systems. This observation is in accordance with the behavior observed by Guo et al. (2012) and Feng et al. (2012) for alcohol-salt ATPS.

It is noteworthy that only few points were obtained at $15^{\circ} \mathrm{C}$ for the ATPS formed by ethanol/sodium citrate because of salt precipitation during titration, resulting in a short binodal curve. Other authors obtained equilibrium data in a narrow range for ethanol/sodium citrate ATPS owing to salt precipitation caused by the low sodium citrate solubility in ethanol (Greve \& Kula, 1991; Ooi et al., 2009; Zafarani-Moattar et al., 2005).

The binodal curves of the two systems were close, indicating that sodium citrate and ammonium sulfate have similar phase formation ability, that is, similar salt concentrations are required to form biphasic aqueous systems with ethanol. A similar result was obtained by Wu et al. (2014) with ATPS composed of ethanol and ammonium sulfate/monosodium phosphate.

Equations (1-3) were fitted to the experimental data of binodal curves, and the estimated values of regression coefficients, coefficient of determination $\left(R^{2}\right)$ and root-mean-square-error (RMSE) of the adjusted equations are listed in Table 1.

All regression coefficients appearing in Table 1 were significant ( $p$-value $<0.05)$, as well as the adjusted models $(p$-value $<0.05)$, while none of the equations fitted satisfactorily 
A

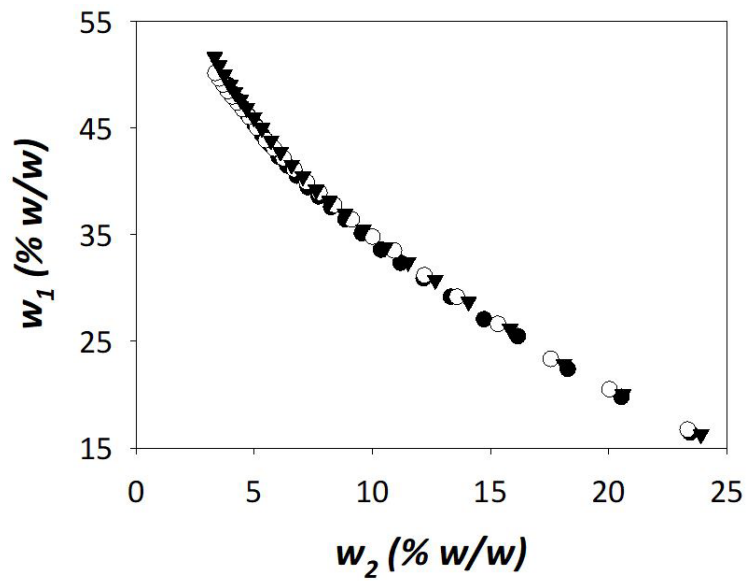

$\mathrm{B}$

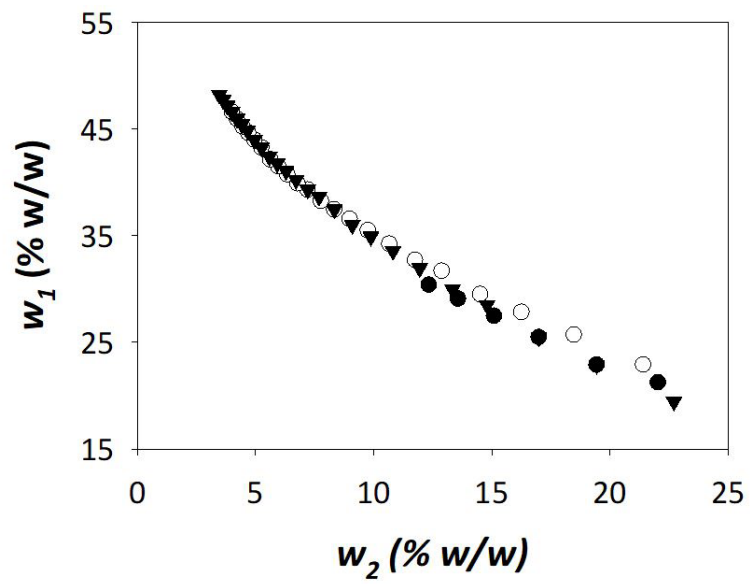

Figure 1. Phase diagrams of (A) ATPS made up of ethanol (1), ammonium sulfate (2) and water; (B) ATPS made up of ethanol (1), sodium citrate (2) and water. Temperature $\left({ }^{\circ} \mathrm{C}\right): 15(\bullet), 25(\circ)$ and $35(\boldsymbol{\nabla})$. Pressure: $0.1 \mathrm{MPa}$. $w$ : concentration $(\%, \mathrm{w} / \mathrm{w})$.

Table 1. Values of Eq. (1-3) regression coefficients, coefficients of determination $\left(R^{2}\right)$ and root-mean-square errors (RMSE) for systems containing ethanol (1), sodium citrate or ammonium sulfate (2) and water at different temperatures $(T)$. Pressure $=0.1 \mathrm{MPa}$.

\begin{tabular}{|c|c|c|c|c|c|c|c|}
\hline$T\left({ }^{\circ} \mathrm{C}\right)$ & Equation & $A$ & $B$ & $C$ & $D$ & $R^{2}$ & RMSE \\
\hline \multicolumn{8}{|c|}{ Ethanol + Sodium citrate + Water } \\
\hline \multirow[t]{3}{*}{25} & 1 & 76.06533 & -0.24043 & 0.00001 & -0.03793 & 0.9961 & 0.4605 \\
\hline & 2 & 70.93835 & -13.21460 & 0.60230 & & 0.9955 & 0.4947 \\
\hline & 3 & 82.39743 & -23.48560 & 3.08255 & & 0.9964 & 0.4412 \\
\hline \multirow[t]{3}{*}{35} & 1 & 75.59711 & -0.23687 & 0.00002 & -0.01774 & 0.9975 & 0.3995 \\
\hline & 2 & 69.76181 & -12.15460 & 0.38240 & & 0.9973 & 0.4177 \\
\hline & 3 & 74.76469 & -16.76270 & 1.51770 & & 0.9975 & 0.4032 \\
\hline \multicolumn{8}{|c|}{ Ethanol + Ammonium sulfate + Water } \\
\hline \multirow[t]{3}{*}{15} & 1 & 82.99490 & 82.99490 & 0.00002 & -0.04112 & 0.9984 & 0.3690 \\
\hline & 2 & 74.75981 & -14.55810 & 0.54342 & & 0.9976 & 0.4479 \\
\hline & 3 & 87.63809 & -26.08740 & 3.30833 & & 0.9987 & 0.3330 \\
\hline \multirow[t]{3}{*}{25} & 1 & 81.92226 & -0.26669 & 0.00002 & -0.01412 & 0.9989 & 0.3223 \\
\hline & 2 & 74.22204 & -14.06940 & 0.46927 & & 0.9988 & 0.3360 \\
\hline & 3 & 78.14175 & -17.79000 & 1.38432 & & 0.9989 & 0.3218 \\
\hline \multirow[t]{3}{*}{35} & 1 & 85.98298 & -0.27800 & 0.00002 & -0.02421 & 0.9995 & 0.2310 \\
\hline & 2 & 77.45670 & -15.29710 & 0.58016 & & 0.9991 & 0.3025 \\
\hline & 3 & 84.83213 & -21.99470 & 2.20048 & & 0.9995 & 0.2333 \\
\hline
\end{tabular}

the data of the system composed of ethanol/sodium citrate at $15^{\circ} \mathrm{C}$ ( $p$-value $\left.>0.05\right)$ due to salt precipitation. The high values of the coefficient of determination $\left(\mathrm{R}^{2} \geq 0.9955\right)$ and the low values of $R M S E(\leq 0.4947)$ indicate that all three models showed satisfactory accuracy in fitting the experimental data, apart from that exception, so that any of the equations may be used to describe the binodal curves of the systems under consideration. To show the reliability of the adjusted models, Figure 2 compares, as an example, the experimental data of ethanol concentration $\left({ }^{w_{I}}\right)$ as function of ammonium sulfate concentration $\left(w_{2}\right)$ with the values estimated by Eq. 3 for this ATPS at $25^{\circ} \mathrm{C}$.

\subsection{Tie-lines}

As will be discussed later, anthocyanins are more stable under acidic rather than alkaline conditions. Ooi et al. (2009) observed that the $\mathrm{pH}$ of ATPS formed by ethanol/1-propanol/2-propanol

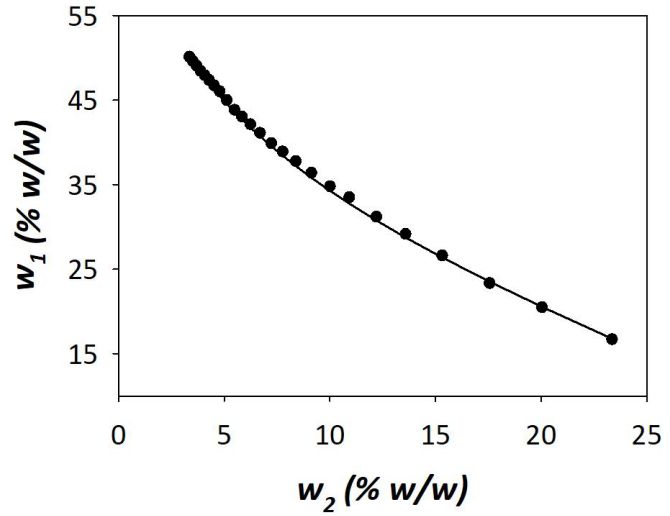

Figure 2. Experimental data of ethanol concentration $\left(w_{1}\right)$ versus ammonium sulfate concentration $\left(w_{2}\right)(\bullet)$ and values calculated by Eq. 3 (-) for the binodal curve of ATPS made up of ethanol, ammonium sulfate and water. Temperature: $25^{\circ} \mathrm{C}$. Pressure: $0.1 \mathrm{MPa}$. 
plus sodium citrate and by ethanol/1-propanol/2-propanol plus ammonium sulfate varied in the ranges 8.0-8.3 and 5.5-6.0, respectively. So, based on the $\mathrm{pH}$ conditions as well as the good solubility and low cost of ammonium sulfate, ethanol/ammonium sulfate ATPS were selected for subsequent experiments.

Based on Eq. 3 model fitted to binodal curve data and lever rule, phase equilibrium compositions were calculated for three overall mixtures only of ethanol/ammonium sulfate ATPS at $25^{\circ} \mathrm{C}$ (Table 2).

It can be seen in the same Table 2 that the higher the overall mixture concentration (higher alcohol and salt concentrations), the higher the ethanol concentration in the top phase as well as the salt concentration in the bottom one and, consequently, the greater the difference in composition between phases. This result agrees with those obtained by Cienfuegos et al. (2017), who studied ATPS constituted by ethanol and different salts.

According to Borges et al. (2016), knowledge of system tie-line length $(T L L)$ is fundamental in studies on analyte partitioning in ATPS, since such a parameter influences target compound distribution between top and bottom phases. TLL reflects differences in phase intensive thermodynamic properties, i.e., those that are independent of the system mass but depend on its composition. The results of Table 2 also show that an increase in salt and alcohol concentrations resulted in a TLL increase, while the slope of tie-line (STL) decreased, becoming more negative. Ammonium sulfate addition to aqueous ethanol solution was likely to promote migration of water molecules away from alcohol to salt ions, so that alcohol molecules were excluded from the bottom salt-rich phase to the top alcohol-rich one (Wang et al., 2010a).

\subsection{Anthocyanins partition in ethanol/ammonium sulfate ATPS}

According to (Wu et al., 2011), ethanol/ammonium sulphate ATPS can be considered cheap systems, which are under consideration to extract anthocyanins from different sources such as grape juice (Wu et al., 2014), mulberry (Wu et al., 2011), Garcinia indica fruits (Nainegali et al., 2017), Nitraria tangutorun Bobr. and Lycium ruthenicum Murr. (Sang et al., 2018). In addition, they provide a mildly acidic medium, which can protect the target compound against degradation under alkaline conditions ( $\mathrm{Wu}$ et al., 2014). Thus, the partitioning behavior anthocyanins from Syzygium cumini fruit peel was investigated in such ATPS at $25^{\circ} \mathrm{C}$.

Partitioning experiments were conducted at different TLL values, whose results in terms of partition coefficient $\left(k_{a}\right)$ and recovery yield in the top phase $\left(\mathrm{Y}_{\mathrm{t}}\right)$ are shown in Figure 3. Values of $k_{a}$ were greater than 1.0 for all tested systems, suggesting that anthocyanins were concentrated in the top alcohol-rich phase. A similar result was observed for partitioning of grape juice anthocyanins in ethanol/ammonium sulfate/monosodium phosphate ATPS at $25^{\circ} \mathrm{C}$ (Wu et al., 2014).

The value of $k_{a}$ raised from 2.3 to 5.0 when TLL was increased from 40.4 to $66.1 \%(\mathrm{w} / \mathrm{w})$. This result suggests that anthocyanins migrated preferentially to the alcohol-rich phase when salt and alcohol concentrations in the system were increased. Higher affinity for the top phase has been observed for the extraction and purification of Dacrydes peel anthocyanins in ATPS composed of ethanol and ammonium sulfate/dipotassium phosphate/potassium dihydrogen phosphate (Al-Alawi et al., 2018) as well as for the extraction and pre-purification of grape juice anthocyanins in ethanol/sodium phosphate ATPS (Tang et al., 2018). Liu et al. (2013) also observed an increase in the partition coefficient of purple sweet potato anthocyanins in ethanol/ammonium sulfate ATPS when salt concentration was increased.

Despite its high water solubility, anthocyanins concentrated in the top alcohol-rich phase due to the salting-out effect caused by the salt. The higher the salt concentration, the stronger the salting-out effect and, consequently, the higher the anthocyanins partition coefficient (Nainegali et al., 2017).

$\mathrm{Y}_{\mathrm{t}}$ behavior was qualitatively similar to that of $k_{a}$, in that, it raised from 69.4 to $83.3 \%$ when TLL was increased from

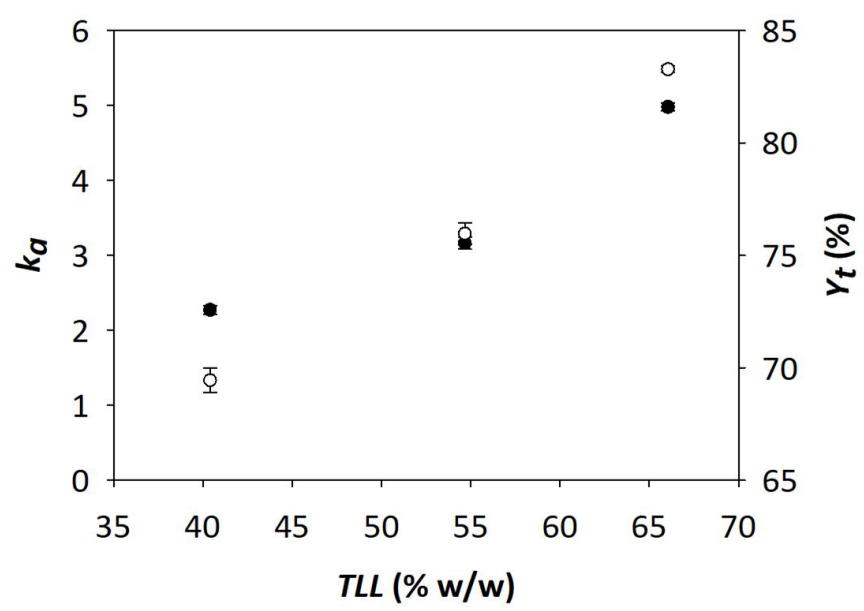

Figure 3. Effects of TLL on anthocyanins partition coefficient $\left(\mathrm{k}_{\mathrm{a}}, \bullet\right)$ and recovery yield in the top phase $\left(\mathrm{Y}_{\mathrm{t}} \%, \mathrm{o}\right)$ for ATPS made up of ethanol, ammonium sulfate and water at $25^{\circ} \mathrm{C}$. Pressure $=0.1 \mathrm{MPa}$. Error bars are standard deviations.

Table 2. Experimental (liquid-liquid) equilibrium concentrations ( $w, \% \mathrm{w} / \mathrm{w})$, tie-lines length (TLL, \% w/w) and slopes (STL) for systems formed by ethanol (1), ammonium sulfate (2) and water at $25^{\circ} \mathrm{C}$. Pressure $=0.1 \mathrm{MPa}$. $w$ : concentration $(\%, \mathrm{w} / \mathrm{w})$.

\begin{tabular}{|c|c|c|c|c|c|c|c|}
\hline \multicolumn{2}{|c|}{ Overall composition } & \multicolumn{2}{|c|}{ Top phase } & \multicolumn{2}{|c|}{ Bottom phase } & \multirow{2}{*}{$T L L$} & \multirow{2}{*}{ STL } \\
\hline$w_{1}$ & $w_{2}$ & $w_{1}$ & $w_{2}$ & $w_{1}$ & $w_{2}$ & & \\
\hline 36.0 & 11.0 & 44.0 & 5.4 & 11.0 & 28.7 & 40.4 & -1.4 \\
\hline 38.0 & 12.0 & 51.7 & 2.9 & 6.2 & 33.1 & 54.7 & -1.5 \\
\hline 40.0 & 13.0 & 58.4 & 1.5 & 2.4 & 36.5 & 66.1 & -1.6 \\
\hline
\end{tabular}


40.4 to $66.1 \%$ (w/w). Nainegali et al. (2017) obtained $k_{a}$ and $\mathrm{Y}_{\mathrm{t}}$ for Garcina indica anthocyanins close to 12.5 and $83 \%$, respectively, in ATPS composed of 25\% (w/w) ethanol and 25\% $(w / w)$ ammonium sulfate.

\section{Conclusions}

Binodal curves for ATPS composed of ethanol/sodium citrate and ethanol/ammonium sulfate were obtained experimentally at 15,25 and $35^{\circ} \mathrm{C}$. A temperature increase within the tested range did not alter the solubility of mixture components so that the biphasic region remained the same for a given salt. We tested three models that proved able to satisfactorily fit the binodal curve data of the investigated systems, except for ethanol/sodium citrate ATPS at $15^{\circ} \mathrm{C}$. Tie-lines and phase equilibrium compositions were obtained for ethanol/ammonium sulfate ATPS. Higher overall mixture concentration resulted in longer tie-line length and, consequently, in more different phase compositions. Partitioning of anthocyanins from Syzygium cumini fruit peel in this ATPS led to preferential migration of molecules to ethanol-rich top phase, and the increase in salt/alcohol concentrations to higher values of partition coefficient and recovery yield.

\section{Acknowledgements}

The authors would like to thank PRPq/UFMG and PROBIC/FAPEMIG for the financial support and the scientific initiation fellowship, respectively.

\section{References}

Al-Alawi, A., Nithyanandam, R., \& Hong, T. L. (2018, June). Integrated extraction and purification of anthocyanin from Dacryodes rostrata peel using aqueous two-phase extraction (ATPE). In: Proceedings 10th International Engineering Research Conference - EURECA (pp. 1-14). Subang Jaya: Taylor's University.

Albertsson, P. A. (1958). Partition of proteins in liquid polymer-polymer two-phase systems. Nature, 182(4637), 709-711. http://dx.doi. org/10.1038/182709a0. PMid:13590079.

Albertsson, P. A. (1986). Partition of cell particles and macromolecules. New York: Wiley.

Ascon-Cabrera, M., \& Lebeault, J.-M. (1993). Selection of xenobioticdegrading microorganisms in a biphasic aqueous-organic system. Applied and Environmental Microbiology, 59(6), 1717-1724. PMid:16348949.

Asenjo, J. A., \& Andrews, B. A. (2011). Aqueous two-phase systems for protein separation: a perspective. Journal of Chromatography. A, 1218(49), 8826-8835. http://dx.doi.org/10.1016/j.chroma.2011.06.051. PMid:21752387.

Atefi, E., Joshi, R., Mann, J. A. Jr., \& Tavana, H. (2015). Interfacial tension effect on cell partition in aqueous two-phase systems. ACS Applied Materials \& Interfaces, 7(38), 21305-21314. http://dx.doi. org/10.1021/acsami.5b05757. PMid:26356592.

Borges, G. A., Silva, L. P., Penido, J. A., Lemos, L. R., Mageste, A. B., \& Rodrigues, G. D. (2016). A method for dye extraction using an aqueous two-phase system: Effect of co-occurrence of contaminants in textile industry wastewater. Journal of Environmental Management, 183, 196-203. http://dx.doi.org/10.1016/j.jenvman.2016.08.056. PMid:27591846.
Chandrasekhar, J., Madhusudhan, M. C., \& Raghavarao, K. S. M. S. (2012). Extraction of anthocyanins from red cabbage and purification using adsorption. Food and Bioproducts Processing, 90(4), 615-623. http://dx.doi.org/10.1016/j.fbp.2012.07.004.

Cienfuegos, N. E. C., Santos, P. L., García, A. R., Soares, C. M. F., Lima, A. S., \& Souza, R. L. (2017). Integrated process for purification of capsaicin using aqueous two-phase systems based on ethanol. Food and Bioproducts Processing, 106, 1-10. http://dx.doi.org/10.1016/j. fbp.2017.08.005.

Feng, Z., Li, J. Q., Sun, X., Sun, L., \& Chen, J. (2012). Liquid-liquid equilibria of aqueous systems containing alcohol and ammonium sulfate. Fluid Phase Equilibria, 317, 1-8. http://dx.doi.org/10.1016/j. fluid.2011.12.023.

Freire, M. G., Louros, C. L. S., Rebelo, L. P. N., \& Coutinho, J. A. P. (2011). Aqueous biphasic systems composed of a water-stable ionic liquid + carbohydrates and their applications. Green Chemistry, 13(6), 1536-1545. http://dx.doi.org/10.1039/c1gc15110j.

Greve, A., \& Kula, M.-R. (1991). Phase diagrams of new aqueous phase systems composed of aliphatic alcohols, salts and water. Fluid Phase Equilibria, 62(1-2), 53-63. http://dx.doi.org/10.1016/03783812(91)87005-T.

Guo, W., Ma, J., Wang, Y., Han, J., Li, Y., \& Song, S. (2012). Liquid-liquid equilibrium of aqueous two-phase systems composed of hydrophilic alcohols (ethanol/2-propanol/1-propanol) and MgSO4/ZnSO4 at (303.15 and 313.15)K and correlation. Thermochimica Acta, 546, 8-15. http://dx.doi.org/10.1016/j.tca.2012.07.022.

Hosseinian, F. S., Li, W., \& Beta, T. (2008). Measurement of anthocyanins and other phytochemicals in purple wheat. Food Chemistry, 109(4), 916-924. http://dx.doi.org/10.1016/j.foodchem.2007.12.083. PMid:26050008.

Iqbal, M., Tao, Y., Xie, S., Zhu, Y., Chen, D., Wang, X., Huang, L., Peng, D., Sattar, A., Shabbir, M. A., Hussain, H. I., Ahmed, S., \& Yuan, Z. (2016). Aqueous two-phase system (ATPS): an overview and advances in its applications. Biological Procedures Online, 18, 18. http://dx.doi.org/10.1186/s12575-016-0048-8. PMid:27807400.

Jampani, C., Naik, A., \& Raghavarao, K. S. M. S. (2014). Purification of anthocyanins from jamun (Syzygium cumini L.) employing adsorption. Separation and Purification Technology, 125, 170-178. http://dx.doi.org/10.1016/j.seppur.2014.01.047.

Khayati, G., \& Gholitabar, A. (2016). Liquid-liquid equilibrium of hydrophilic alcohols with three different salts of chloride: experiment and correlation. Journal of Chemical \& Engineering Data, 61(4), 1454-1461. http://dx.doi.org/10.1021/acs.jced.5b00771.

Khoo, H. E., Azlan, A., Tang, S. T., \& Lim, S. M. (2017). Anthocyanidins and anthocyanins: colored pigments as food, pharmaceutical ingredients, and the potential health benefits. Food \& Nutrition Research, 61(1), 1361779. http://dx.doi.org/10.1080/16546628.201 7.1361779. PMid:28970777.

Liu, X., Mu, T., Sun, H., Zhang, M., \& Chen, J. (2013). Optimisation of aqueous two-phase extraction of anthocyanins from purple sweet potatoes by response surface methodology. Food Chemistry, 141(3), 3034-3041. http://dx.doi.org/10.1016/j.foodchem.2013.05.119. PMid:23871056.

Liu, X., Xiao, G., Chen, W., Xu, Y., \& Wu, J. (2004). Quantification and purification of mulberry anthocyanins with macroporous resins. Journal of Biomedicine \& Biotechnology, 2004(5), 326-331. http:// dx.doi.org/10.1155/S1110724304403052. PMid:15577197.

Lo, S. C., Ramanan, R. N., Tey, B. T., Ling, T. C., Show, P. L., \& Ooi, C. W. (2015). Liquid-liquid equilibrium of alcohols + ammonium/ potassium/sodium acetate + water systems: experimental and 
correlation. Journal of Chemical \& Engineering Data, 60(10), 28482857. http://dx.doi.org/10.1021/acs.jced.5b00200.

Merchuk, J. C., Andrews, B. A., \& Asenjo, J. A. (1998). Aqueous twophase systems for protein separation. Journal of Chromatography. B, Biomedical Sciences and Applications, 711(1-2), 285-293. http:// dx.doi.org/10.1016/S0378-4347(97)00594-X. PMid:9699997.

Michel, B., Neves, M. T., Sousa, R. C. S. d., Chagas, M. M. d., Martins, B. A., \& Coimbra, J. S. R. (2015). Partição de proteínas de soro de leite em sistemas aquosos bifásicos baseados em líquidos iônicos. Quimica Nova, 38, 1148-1152.

Nainegali, B., Iyyaswami, R., \& Belur, P. (2017). Aqueous two-phase extraction of anthocyanin from fruits of garcinia indica. International Journal of Earth Sciences and Engineering, 10(3), 688-692. http:// dx.doi.org/10.21276/ijee.2017.10.0330.

Nemati-Kande, E., Shekaari, H., \& Jafari, S. A. (2012). Liquid-liquid equilibrium of some aliphatic alcohols + disodium tartrate + water aqueous two-phase systems at $298.15 \mathrm{~K}$. Journal of Chemical \& Engineering Data, 57(8), 2336-2342. http://dx.doi.org/10.1021/ je300533r.

Oliveira, A. C., Sosa, F. H. B., Costa, M. C., Monteiro, E. S. Fo., \& Ceriani, R. (2018). Study of liquid-liquid equilibria in aqueous two-phase systems formed by poly (ethylene glycol) (PEG) and sodium thiosulfate pentahydrate $(\mathrm{Na} 2 \mathrm{~S} 2 \mathrm{O} 3.5 \mathrm{H} 2 \mathrm{O})$ at different temperatures. Fluid Phase Equilibria, 476, 118-125. http://dx.doi. org/10.1016/j.fluid.2018.07.035.

Ooi, C. W., Tey, B. T., Hii, S. L., Kamal, S. M. M., Lan, J. C. W., Ariff, A., \& Ling, T. C. (2009). Purification of lipase derived from Burkholderia pseudomallei with alcohol/salt-based aqueous two-phase systems. Process Biochemistry, 44(10), 1083-1087. http://dx.doi.org/10.1016/j. procbio.2009.05.008.

Pereira, J. F. B., Vicente, F., Santos-Ebinuma, V. C., Araújo, J. M., Pessoa, A., Freire, M. G., \& Coutinho, J. A. P. (2013). Extraction of tetracycline from fermentation broth using aqueous two-phase systems composed of polyethylene glycol and cholinium-based salts. Process Biochemistry, 48(4), 716-722. http://dx.doi.org/10.1016/j. procbio.2013.02.025.

Qin, B., Liu, X., Cui, H., Ma, Y., Wang, Z., \& Han, J. (2017). Aqueous two-phase assisted by ultrasound for the extraction of anthocyanins from Lycium ruthenicum Murr. Preparative Biochemistry \& Biotechnology, 47(9), 881-888. http://dx.doi.org/10.1080/1082606 8.2017.1350980. PMid:28708469.

Reis, I. A. O., Santos, S. B., Pereira, F. D. S., Sobral, C. R. S., Freire, M. G., Freitas, L. S., Soares, C. M. F., \& Lima, Á. S. (2014). Extraction and recovery of rutin from acerola waste using alcohol-salt-based aqueous two-phase systems. Separation Science and Technology, 49(5), 656-663. http://dx.doi.org/10.1080/01496395.2013.860461.
Sang, J., Dang, K., Ma, Q., Li, B., Huang, Y.-y., \& Li, C. (2018). Partition behaviors of different polar anthocyanins in aqueous two-phase systems and extraction of anthocyanins from nitraria tangutorun bobr. and lycium ruthenicum murr. Food Analytical Methods, 11(4), 980-991. http://dx.doi.org/10.1007/s12161-017-1071-3.

Show, P. L., Ooi, C. W., Anuar, M. S., Ariff, A., Yusof, Y. A., Chen, S. K., Annuar, M. S. M., \& Ling, T. C. (2013). Recovery of lipase derived from Burkholderia cenocepacia ST8 using sustainable aqueous twophase flotation composed of recycling hydrophilic organic solvent and inorganic salt. Separation and Purification Technology, 110, 112-118. http://dx.doi.org/10.1016/j.seppur.2013.03.018.

Shukla, S. K., Pandey, S., \& Pandey, S. (2018). Applications of ionic liquids in biphasic separation: aqueous biphasic systems and liquid-liquid equilibria. Journal of Chromatography. A, 1559, 44-61. http://dx.doi. org/10.1016/j.chroma.2017.10.019. PMid:29054438.

Tang, X., Wang, Y., Han, J., Wang, L., Li, C., \& Ni, L. (2018). Separation, purification of anthocyanin and vitis linn polysaccharide from grape juice by the two-step extraction and dialysis. Journal of Food Processing and Preservation, 42(1), e13344. http://dx.doi.org/10.1111/jfpp.13344.

Tonova, K., \& Bogdanov, M. G. (2017). Partitioning of a-amylase in aqueous biphasic system based on hydrophobic and polar ionic liquid: Enzyme extraction, stripping, and purification. Separation Science and Technology, 52(5), 812-823. http://dx.doi.org/10.1080/ 01496395.2016.1267211.

Wang, Y., Mao, Y., Han, J., Liu, Y., \& Yan, Y. (2010a). Liquid-liquid equilibrium of potassium phosphate/potassium citrate/sodium citrate + ethanol aqueous two-phase systems at (298.15 and 313.15) $\mathrm{K}$ and correlation. Journal of Chemical \& Engineering Data, 55(12), 5621-5626. http://dx.doi.org/10.1021/je100501f.

Wang, Y., Yan, Y., Hu, S., Han, J., \& Xu, X. (2010b). Phase diagrams of ammonium sulfate + ethanol/1-propanol/2-propanol + water aqueous two-phase systems at $298.15 \mathrm{~K}$ and correlation. Journal of Chemical \& Engineering Data, 55(2), 876-881. http://dx.doi. org/10.1021/je900504e.

Wu, X., Liang, L., Zou, Y., Zhao, T., Zhao, J., Li, F., \& Yang, L. (2011). Aqueous two-phase extraction, identification and antioxidant activity of anthocyanins from mulberry (Morus atropurpurea Roxb.). Food Chemistry, 129(2), 443-453. http://dx.doi.org/10.1016/j. foodchem.2011.04.097. PMid:30634250.

Wu, Y., Wang, Y., Zhang, W., Han, J., Liu, Y., Hu, Y., \& Ni, L. (2014). Extraction and preliminary purification of anthocyanins from grape juice in aqueous two-phase system. Separation and Purification Technology, 124, 170-178. http://dx.doi.org/10.1016/j.seppur.2014.01.025.

Zafarani-Moattar, M. T., Banisaeid, S., \& Beirami, M. A. S. (2005). Phase diagrams of some aliphatic alcohols + potassium or sodium citrate + water at $25^{\circ} \mathrm{C}$. Journal of Chemical \& Engineering Data, 50(4), 1409-1413. http://dx.doi.org/10.1021/je050086h. 